\title{
Comparison of point and 2-dimensional shear wave elastography for the evaluation of liver fibrosis
}

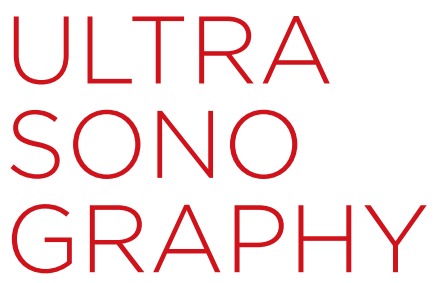

Sang Min Lee', Min-Jeong Kim ${ }^{1}$, Jeong Hee Yoon ${ }^{2,3}$, Wonju Hong ${ }^{1}$, Hong II Ha', Kwanseop Lee', Ji-Young Choe ${ }^{4}$, Jung Woo Lee ${ }^{5}$, Sam-Youl Yoon ${ }^{5}$, Junhee Han ${ }^{6}$

'Department of Radiology, Hallym University Sacred Heart Hospital, Anyang; ${ }^{2}$ Department of Radiology, Seoul National University Hospital, Seoul; ${ }^{3}$ Department of Radiology, Seoul National University College of Medicine, Seoul; Departments of ${ }^{4}$ Pathology and ${ }^{5}$ Surgery, Hallym University Sacred Heart Hospital, Anyang; ${ }^{6}$ Department of Statistics and Institute of Statistics, Hallym University, Chuncheon, Korea

Purpose: This study aimed to assess the technical performance of ElastQ Imaging compared with ElastPQ and to investigate the correlation between liver stiffness (LS) values obtained using these two techniques.

Methods: This retrospective study included 249 patients who underwent LS measurements using both ElastPQ and ElastQ Imaging equipped on the same machine. The applicability, repeatability (coefficient of variation [CV]), acquisition time, and LS values were compared using the chisquare or Wilcoxon signed-rank tests. In the development group, the correlation between the LS values obtained by the two techniques was assessed with Spearman correlation coefficients and linear regression analysis. In the validation group, the agreement between the estimated and real $L S$ values was evaluated using a Bland-Altman plot.

Results: ElastQ Imaging had higher applicability $(94.0 \%$ vs. $78.3 \%, P<0.001)$ and higher repeatability, with a lower median CV $(0.127$ vs. $0.164, \mathrm{P}<0.001)$ than did ElastPQ. The median acquisition time of ElastQ Imaging was significantly shorter than that of ElastPQ (45.5 seconds vs. 96.5 seconds, $\mathrm{P}<0.001)$. The median $\mathrm{LS}$ value obtained using ElastQ Imaging was significantly higher than that obtained using ElastPQ $(5.60 \mathrm{kPa}$ vs. $5.23 \mathrm{kPa}, \mathrm{P}<0.001)$. The $\mathrm{LS}$ values between the two techniques exhibited a strong positive correlation $(r=0.851, P<0.001)$ in the development group. The mean difference and $95 \%$ limits of agreement were $0.0 \mathrm{KPa}(-3.9$ to 3.9 $\mathrm{kPa}$ ) in the validation group.

Conclusion: ElastQ Imaging may be more reliable and faster than ElastPQ, with strongly correlated LS measurements.

Keywords: Liver fibrosis; Ultrasonography; Elastography; ARFI Imaging

\begin{abstract}
This is an Open Access article distributed under the terms of the Creative Commons Attribution NonCommercial License (http://creativecommons.org/ licenses/by-nc/4.0/) which permits unrestricted noncommercial use, distribution, and reproduction in any medium, provided the original work is properly cited.
\end{abstract}

Copyright @ 2020 Korean Society of Ultrasound in Medicine (KSUM)

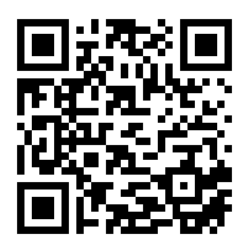

How to cite this article:

Lee SM, Kim MJ, Yoon JH, Hong W, Ha HI, Lee K, et al. Comparison of point and 2-dimensional shear wave elastography for the evaluation of liver fibrosis. Ultrasonography. 2020 Jul;39(3):288-297. 


\section{Introduction}

Liver fibrosis, which is increasing in prevalence, is one of the most important health issues worldwide [1]. Since liver fibrosis can progress to cirrhosis and lead to hepatocellular carcinoma, it is very important to detect, stage, and monitor liver fibrosis $[2,3]$. Liver fibrosis is staged using the METAVIR scoring system based on samples obtained by liver biopsy [4]. Although liver biopsy is the gold standard for the assessment of hepatic fibrosis, it is not a suitable tool for monitoring due to its invasiveness and cost. Additionally, sampling errors may occur because of the very small size of the obtained samples and high intra- and inter-observer variability among pathologists $[5,6]$. Thus, many non-invasive tests, including serum-based markers and elastography, have emerged as alternatives to liver biopsy.

Ultrasonography (US)-based elastography has been regarded as a promising method due to its high diagnostic performance and easy access [7]. This technique is based on the principle that the speed of US waves is faster inside hard tissue than inside soft tissue, making it possible to measure shear wave speed and liver stiffness (LS) values using US-based elastography. Currently, transient elastography (TE) is the most extensively validated form of US-based elastography because it was the first commercially available USbased elastography technique, and many studies have established its high diagnostic performance for liver fibrosis [8-10]. However, TE also has some limitations, including relatively high failure rates in patients with obesity, ascites, and narrow intercostal spaces [11,12].

Unlike TE, newer US-based elastography techniques, including point shear wave elastography (pSWE) and 2-dimensional shear wave elastography (2D-SWE), acquire grayscale images of the liver and can be used to appropriately evaluate LS by placing the region of interest (ROI) using the same probe as that used in the conventional diagnostic US system [13-16]. In addition, pSWE and 2D-SWE have shown comparable or better diagnostic performance and a lower rate of technical failure than TE when evaluating liver fibrosis [1,17-20]. Virtual touch quantification (VTQ; Siemens Healthcare, Erlangen, Germany) of acoustic radiation force impulse was the first pSWE system to be developed and has been validated by many large-scale studies $[18,21,22]$. A relatively new pSWE technique, ElastPQ, showed good diagnostic performance in predicting significant fibrosis ( $\geq F 2$ ) and cirrhosis (F4) with a high success rate and reliable measurements [23-26]. The recent advent of 2D-SWE has allowed for the visualization of multiple shear waves and has enabled both qualitative and quantitative evaluation of LS by providing real-time colored elastographic maps of tissue stiffness. The latest 2D-SWE system, ElastQ Imaging, provides the largest elastographic map available and a unique confidence map that helps physicians select an adequate measuring area. However, few published studies have investigated the clinical applicability of ElastQ Imaging in the evaluation of liver fibrosis.

Therefore, the purpose of this study was to assess the technical performance of ElastQ Imaging compared with ElastPQ equipped on the same US machine, and to investigate the correlation between the $L S$ values obtained using the two techniques.

\section{Materials and Methods}

This retrospective study was approved by our institutional review board, and the requirement for informed consent was waived. From March 2017 to December 2018, we searched our radiology database to identify patients who met the following eligibility criteria: (1) being older than 18 years; (2) being referred to the US unit for SWE to determine the presence of liver fibrosis; and (3) undergoing PSWE and 2D-SWE using the same US equipment on the same day. Patients were excluded based on the following criteria: (1) the presence of cofounding factors that might affect LS values (e.g., acute hepatitis, obstructive cholestasis, or hepatic venous congestion) [27]; and (2) insufficient LS measurements (e.g., fewer than 10 measurements for ElastPQ or ElastQ Imaging). A total of 275 patients met all eligibility criteria, and 26 patients were excluded due to the presence of biliary obstruction or heart failure $(n=9)$ and insufficient $L S$ measurements $(n=17)$. As a result, 249 patients were included in our study, and we assessed the technical success rate and reliability of the measurements of the two SWE techniques. After excluding cases with technical failure and unreliable measurements, 189 patients were finally included in our comparison of the repeatability, acquisition time, and LS values obtained by the two SWE techniques (Fig. 1).

The medical records of the enrolled patients were reviewed by two radiologists (M.J.K. and W.H.) with 15 years and 3 years of clinical experience in abdominal imaging, respectively. Clinical and biochemical parameters, including patient age, sex, body mass index, platelet count, and levels of aspartate aminotransferase, were obtained from hospital medical records. The data were obtained within 1 week before or after the LS measurements. The LS values obtained by ElastPQ were used for the assignment of hepatic fibrosis stages, in accordance with the reference values provided by a previous study [24].

\section{LS Measurements Using ElastPQ and ElastQ Imaging}

Measurements using both ElastPQ and ElastQ Imaging were made with the same US equipment (EPIQ 7G, Philips Healthcare, Cleveland, OH, USA) by a single operator (S.M.L.) who had 3 years of experience with US elastography and 10 years of experience 
with US. At least 10 LS measurements were acquired for each SWE technique with the same convex probe (C5-1) used for conventional B-mode US examinations. All patients fasted for longer than 6 hours before the examination and were placed in the supine position with the right arm extended above the head. According to a recently developed guideline, the patients were asked to hold their breath during the $L S$ measurements in order to minimize breathing motions [1]. A measuring box was placed in the right anterior section of the liver, in a location free from areas with artifacts and 1.5-2.0 $\mathrm{cm}$ away from Glisson's capsule, using a convex probe and the intercostal approach $[1,28]$.

For LS measurements using ElastPQ, a measuring box of 1.5 $\mathrm{cm} \times 0.5 \mathrm{~cm}$ was placed in the right anterior section of the liver, avoiding large vessels and bile ducts (Fig. 2A). As ElastQ Imaging was performed, a large, trapezoid-shaped, colored elastographic box was placed in a similar position of the liver with simultaneous

275 Consecutive patients underwent LS measurements using both ElastPQ and ElastQ Imaging

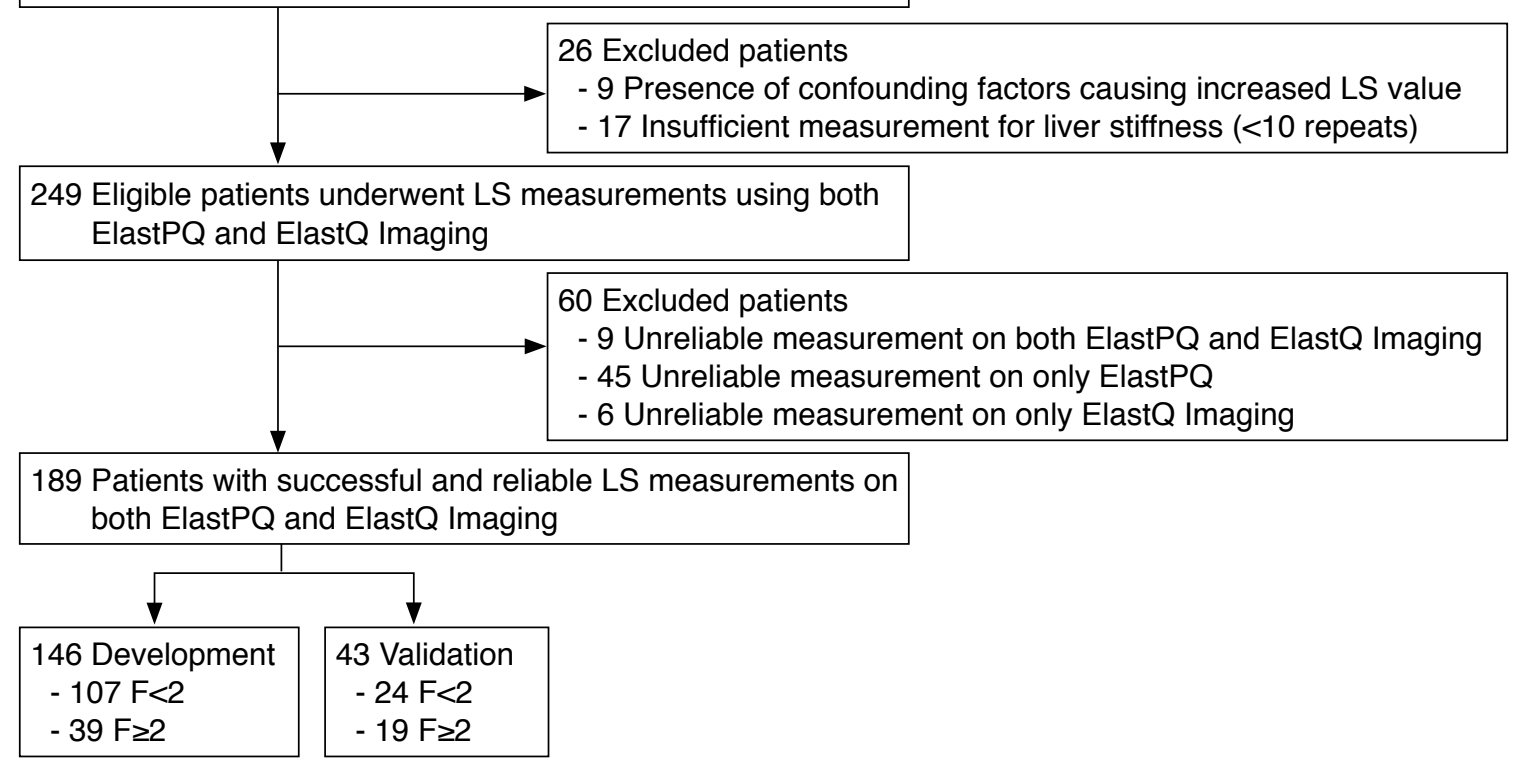

Fig. 1. Flow diagram of the study population. $L S$, liver stiffness; $F$, fibrosis stage $(F<2$, no significant liver fibrosis; $F \geq 2$; significant fibrosis).

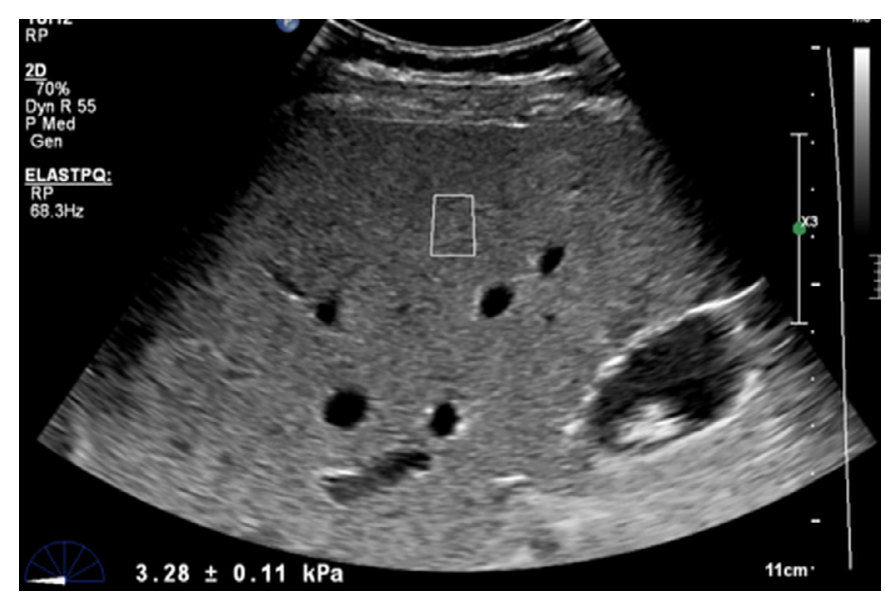

A

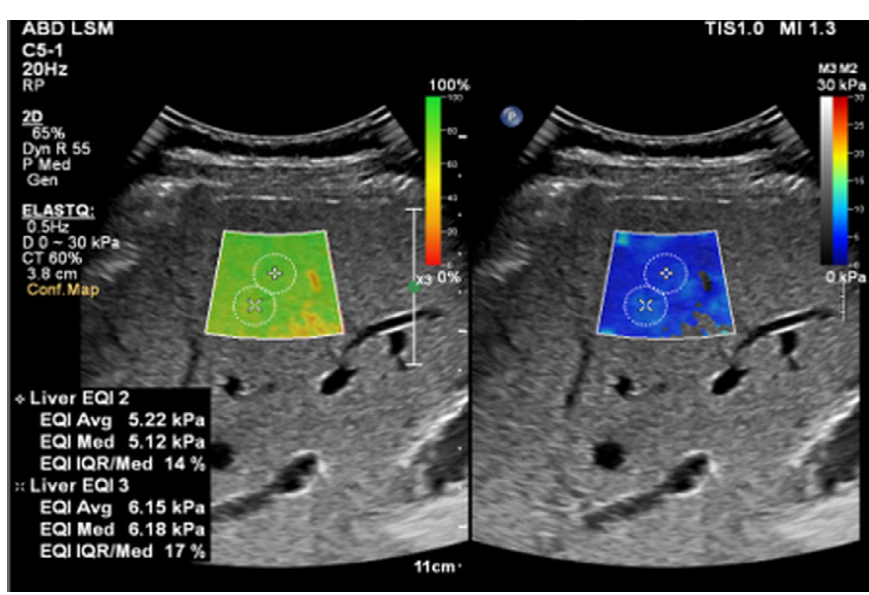

B

Fig. 2. Liver stiffness (LS) measurements using ElastPQ (A) and ElastQ Imaging (B).

A. For $L S$ measurements using ElastPQ, a measuring box $(1.5 \mathrm{~cm} \times 0.5 \mathrm{~cm})$ is placed in the right anterior section of the liver, avoiding large vessels and bile ducts. B. For LS measurements using ElastQ Imaging, a large, trapezoid-shaped, colored elastographic box (right) is placed in the right anterior section of the liver with simultaneous use of the confidence map (left). Regions of interest (diameter, $1 \mathrm{~cm}$ ) are placed within the elastographic box in the area where the confidence map is green. 
use of the confidence map, which shows areas of high confidence in green and areas of low confidence in red. Two or three round ROIs (diameter, $1 \mathrm{~cm}$ ) were placed within the third elasticity map after passing the first and second elasticity maps (Fig. 2B) [29-31]. To obtain 10 valid measurements, $4-5$ breath holds were required when using ElastQ Imaging, whereas more than 10 breath holds are generally required for ElastPQ.

\section{Definition of Applicability, Repeatability, and Acquisition Time}

The applicability of the SWE techniques was determined by the ratio of examinations without technical failure or unreliable measurements to all examinations $[32,33]$. Technical failure of ElastPQ was defined as the inability to obtain 10 valid measurements after at least 15 trials [26]. Technical failure of ElastQ Imaging was defined as the inability to obtain a color map in more than $50 \%$ of the sampling area for all acquisitions [34]. For both ElastPQ and ElastQ Imaging, unreliable measurements were defined as those where the ratio of the interquartile range (IQR) to the median of 10 valid $L S$ values was higher than 30\% [1,12].

At each session, more than 10 sequential LS values were measured and used to determine the median LS value, the mean LS value, and the standard deviation (SD). The median LS value from each session was regarded as the representative $L S$ value in each patient. To evaluate the repeatability of $L S$ measurements in each session, the coefficient of variation (CV) was calculated as follows: $\mathrm{CV}=\mathrm{SD} /$ mean LS value [35]. A lower CV indicated higher measurement repeatability.

Acquisition time was defined as the time from the start to the end of obtaining 10 valid LS measurements with each SWE technique. In cases of technical failure (i.e., when 10 valid LS measurements could not be obtained during at least 15 trials), the acquisition time was determined as the time spent measuring all $15 \mathrm{LS}$ values.

\section{Statistical Analysis}

Categorical variables (e.g., technical success rate) were compared between the two techniques were compared using the chi-square or Fisher exact test. Results from the Kolmogorov-Smirnov test revealed that all continuous variables (e.g., LS values) were non-normally distributed, and these results were expressed as the median with IQR. The Wilcoxon signed-rank test was used to compare continuous variables between the two techniques. To determine the level of agreement between the $L S$ values obtained using the two techniques, Bland-Altman plot analysis was used [36].

We chronologically divided the enrolled patients into a development group (between March and December 2017) and a validation group (between January and December 2018). Each group was subdivided into two subgroups of patients (with and without significant fibrosis) using a cutoff $L S$ value of $6.8 \mathrm{kPa}$ based on ElastPQ [24]. In the development group and its subgroups, we evaluated the correlation between the LS values obtained by the two SWE techniques using Spearman correlation coefficients and linear regression analysis. A correlation was considered strong if the absolute value of $r$ was $>0.7$ and moderate if $0.3<r<0.7$. We determined the linear regression equation for $\mathrm{LS}$ values as ElastQ $(y)$ and ElastPQ $(x)$. In the validation group and its subgroups, the estimated values of ElastQ Imaging using a linear regression equation were obtained, and we assessed the agreement between the estimated and real LS values obtained by ElastQ Imaging using Bland-Altman plot analysis. All statistical analyses were performed using commercially available software programs (version 24, IBM Corp., Armonk, NY, USA; version 18.11.6, MedCalc Software, Mariakerke, Belgium). For all analyses, P-values of $<0.05$ were considered to indicate statistical significance.

\section{Results}

A total of 249 patients (136 men and 113 women; mean age, $54.4 \pm 13.6$ years) were included in this study. Clinical history and serological tests for markers such as hepatitis B antigen, hepatitis C antibody, transaminases, alkaline phosphatase, and bilirubin levels revealed evidence of chronic liver disease in $132(53.0 \%)$ of these patients, with the following distribution: chronic hepatitis B (32.5\%), chronic alcoholic hepatitis (8.4\%), chronic hepatitis C (6.4\%), and idiopathic chronic hepatitis (5.6\%) [37]. According to the presumed liver fibrosis staging [24], 131 patients (69.3\%) had no significant fibrosis $(<F 2)$ and the remaining 58 patients (30.7\%) had significant fibrosis ( $\geq F 2$ ) (Table 1).

\section{Comparison of Applicability between ElastPQ and ElastQ Imaging}

Technical failure was not observed in either ElastPQ or ElastQ Imaging in any of the 249 patients. Of the 249 patients, reliable LS measurements were obtained in $78.3 \%$ (195 of 249) of the where ElastPQ was used and $94.0 \%$ (234 of 249) of the cases where ElastQ Imaging was used $(\mathrm{P}<0.001)$.

\section{Comparison of Repeatability, Acquisition Time, and LS Values Obtained Using ElastPQ and ElastQ Imaging}

In the 189 patients who had reliable LS measurements in both ElastPQ and ElastQ Imaging, significant differences were found between the two SWE techniques in terms of the CVs, acquisition time, and LS values (Table 2). The CVs obtained using ElastQ Imaging were significantly lower than those obtained using ElastPQ $(0.127$ 
[IQR, 0.094 to 0.163$]$ vs. 0.164 [IQR, 0.133 to 0.199$]$, respectively; $\mathrm{P}<0.001)$. The median acquisition time of ElastQ Imaging was significantly shorter than that of ElastPQ (45.5 seconds [IQR, 31.0 to 61.0 seconds] vs. 96.5 seconds [IQR, 85.0 to 119.0 seconds], respectively; $P<0.001)$. The median $L S$ value obtained using ElastQ Imaging (5.60 kPa [IQR, 4.66 to $8.34 \mathrm{kPa}]$ ) was significantly higher than that obtained using ElastPQ (5.23 kPa [IQR, 4.20 to $7.78 \mathrm{kPa}$ ]; $P<0.001)$. The $95 \%$ Bland-Altman limit of agreement between the $L S$ values obtained using ElastPQ and ElastQ Imaging was -0.5 of the mean (Fig. 3).

\section{Correlation of LS Values between ElastPQ and ElastQ Imaging in the Development Group}

The development group consisted of 146 patients ( 85 men and 61 women; mean age, 53.1 \pm 13.3 years) and was subdivided into subgroups of patients with significant fibrosis ( $\geq 6.8 \mathrm{kPa}$ obtained

Table 1. Patients' characteristics

\begin{tabular}{lc}
\hline \multicolumn{1}{c}{ Characteristic } & Value $(\mathrm{n}=249)$ \\
\hline Age $(\mathrm{yr})$ & $54.4 \pm 13.6(19-83)$ \\
Sex & $136(54.6)$ \\
Men & $113(45.4)$ \\
Women & $24.3 \pm 3.7(16.3-41.0)$ \\
Body mass index $\left(\mathrm{kg} / \mathrm{m}^{2}\right)^{\mathrm{a})}$ & \\
Underlying liver disease & $81(32.5)$ \\
Chronic hepatitis B & $16(6.4)$ \\
Chronic hepatitis C & $21(8.4)$ \\
Chronic alcoholic hepatitis & $14(5.6)$ \\
Chronic hepatitis with idiopathic origin & $117(47.0)$ \\
None & \\
Presumed liver fibrosis staging $(\mathrm{n}=189)^{\mathrm{b})}$ & $131(69.3)$ \\
$\mathrm{F}<2$ & $58(30.7)$ \\
$\mathrm{F} \geq 2$ &
\end{tabular}

Values are presented as mean \pm standard deviation (range) or number (\%).

${ }^{a}$ Data available from 189 patients. ${ }^{\text {b) }}$ Data available from 189 patients; the cutoff value used to classify stage 2 liver fibrosis stage 2 was $6.8 \mathrm{kPa}(\mathrm{F} \geq 2$, significant fibrosis) obtained by ElastPQ [19].

Table 2. Comparison of repeatability, acquisition time, and LS values between ElastPQ and ElastQ Imaging

\begin{tabular}{lccc}
\hline & ElastPQ & ElastQ Imaging & P-value \\
\hline CV & $0.164(0.133-0.199)$ & $0.127(0.094-0.163)$ & $<0.001$ \\
Acquisition time & $96.5(85.0-119.0)$ & $45.5(31.0-61.0)$ & $<0.001$ \\
$(\mathrm{sec})$ & $5.23(4.20-7.78)$ & $5.60(4.66-8.34)$ & $<0.001$ \\
\hline LS values $(\mathrm{kPa})$ &
\end{tabular}

Values are presented as median (interquartile range).

$L S$, liver stiffness; $C V$, coefficient of variation. by ElastPQ, $\mathrm{n}=39)$ and without significant fibrosis $(<6.8 \mathrm{kPa}$ obtained by ElastPQ, $n=107$ ). In 146 patients, the $L S$ values for both ElastPQ and ElastQ Imaging exhibited a strong, positive correlation $(r=0.851, P<0.001)$. The linear regression equation for the $L S$ values obtained using ElastQ Imaging $(y)$ and those using ElastPQ $(x)$ was $y=0.86+0.96 x\left(R^{2}=0.72, P<0.001\right)$ (Fig. 4A). Moderate positive correlations between the LS values obtained by the two SWE techniques were observed in the subgroups without significant fibrosis $(r=0.494, P<0.001)$ and with significant fibrosis $(r=0.692$, $P<0.001)$. In the subgroup without significant fibrosis, the linear regression equation for the $L S$ values obtained using ElastQ Imaging $(y)$ and those using ElastPQ $(x)$ was $y=2.47+0.59 x\left(R^{2}=0.244\right.$, $\mathrm{P}<0.001)$ (Fig. 4B). In the subgroup with significant fibrosis, the linear regression equation for the $L S$ values obtained using ElastQ Imaging $(y)$ and those using ElastPQ $(x)$ was $y=1.52+0.92 x\left(R^{2}=0.48\right.$, $\mathrm{P}<0.001$ ) (Fig. 4C).

\section{Validation of the LS Values Estimated Using the Linear Regression Equation}

The validation group consisted of 43 patients (26 men and 17 women; mean age, $58.9 \pm 13.2$ years) and was subdivided into subgroups of patients with significant fibrosis ( $\geq 6.8 \mathrm{kPa}$ obtained by ElastPQ, $\mathrm{n}=19)$ and without significant fibrosis $(<6.8 \mathrm{kPa}$ obtained by ElastPQ, $n=24$ ). The estimated $L S$ values of ElastQ Imaging in the validation group and its subgroups were calculated using the linear

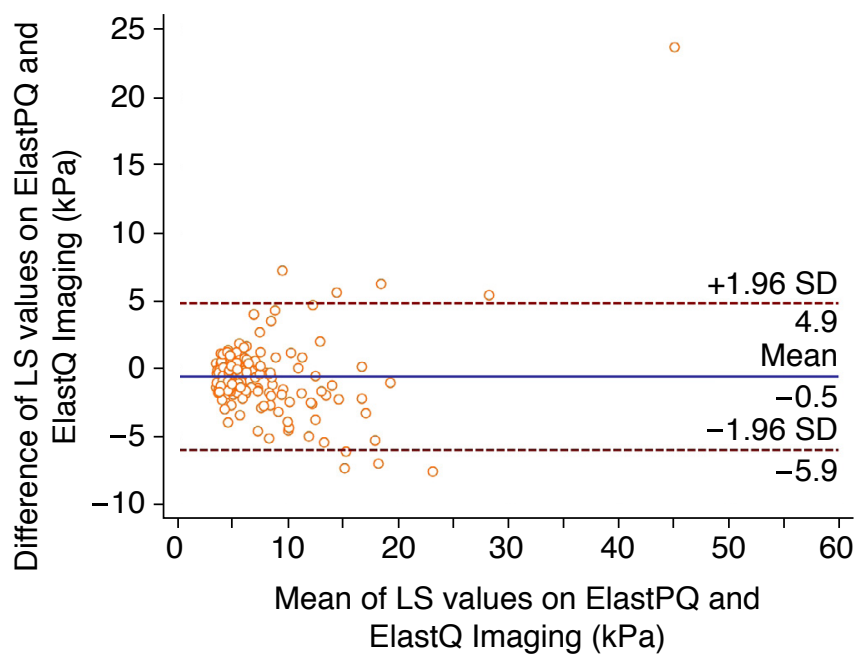

Fig. 3. Bland-Altman plot of liver stiffness (LS) values between ElastPQ and ElastQ Imaging. The mean difference in the $L S$ values between ElastPQ and ElastQ Imaging was $-0.5 \mathrm{kPa}$ with $95 \%$ limits of agreement ranging from $-5.9 \mathrm{kPa}$ to $4.9 \mathrm{kPa}$. The solid line indicates the mean difference. The top and bottom dashed lines correspond to the upper and lower margins of the $95 \%$ limits of agreement. SD, standard deviation. 
regression equation obtained from the development group. The median (IQR) values of the estimated and real $L S$ values for ElastQ Imaging were $5.74 \mathrm{kPa}$ (4.85 to $7.77 \mathrm{kPa}$ ) and $5.44 \mathrm{kPa}$ (4.65 to $7.28 \mathrm{kPa}$ ), respectively (Table 3). Bland-Altman plots of agreement between the real and estimated LS values are shown in Fig. 5. The mean differences ( $95 \%$ limits of agreement) were $0.0 \mathrm{kPa}$ (-3.9 to $3.9 \mathrm{kPa}$ ) in the validation group (Fig. 5A), $0.3 \mathrm{kPa}(-2.4$ to $2.9 \mathrm{kPa})$ in the subgroup without significant fibrosis (Fig. $5 \mathrm{~B}$ ), and $-1.0 \mathrm{kPa}$ $(-12.2$ to $10.3 \mathrm{kPa}$ ) in the subgroup with significant fibrosis (Fig. $5 C)$.

\section{Discussion}

This is the first study to directly compare the applicability, repeatability, acquisition time, and LS values between a 2D-SWE technique (ElastQ Imaging) and a pSWE technique (ElastPQ) using the same US equipment. ElastQ Imaging showed higher applicability, repeatability, and LS values and a faster acquisition time than did ElastPQ. Additionally, the LS values obtained using the two

Table 3. The estimated and real LS values obtained using ElastQ Imaging in the validation group

\begin{tabular}{ccc}
\hline & Estimated LS value $(\mathrm{kPa})^{\mathrm{a})}$ & Real LS value $(\mathrm{kPa})$ \\
\hline All $(\mathrm{n}=43)$ & $5.74(4.85-7.77)$ & $5.44(4.65-7.28)$ \\
$\mathrm{F}<2(\mathrm{n}=24)^{\mathrm{b})}$ & $5.28(4.66-5.61)$ & $4.98(4.50-5.90)$ \\
$\left.\mathrm{F} \geq 2(\mathrm{n}=19)^{\mathrm{c}}\right)$ & $11.47(9.63-15.54)$ & $11.85(8.41-17.93)$ \\
\hline
\end{tabular}

Values are presented as median (interquartile range).

$L S$, liver stiffness.

${ }^{a}$ Calculated from the $L S$ values obtained using ElastPQ via the linear regression equation derived for the development group. ${ }^{b}$ Subgroup without significant fibrosis (<6.8 kPa obtained by ElastPQ) [19]. ")Subgroup with significant fibrosis ( $\geq 6.8 \mathrm{kPa}$ obtained by ElastPQ) [19].

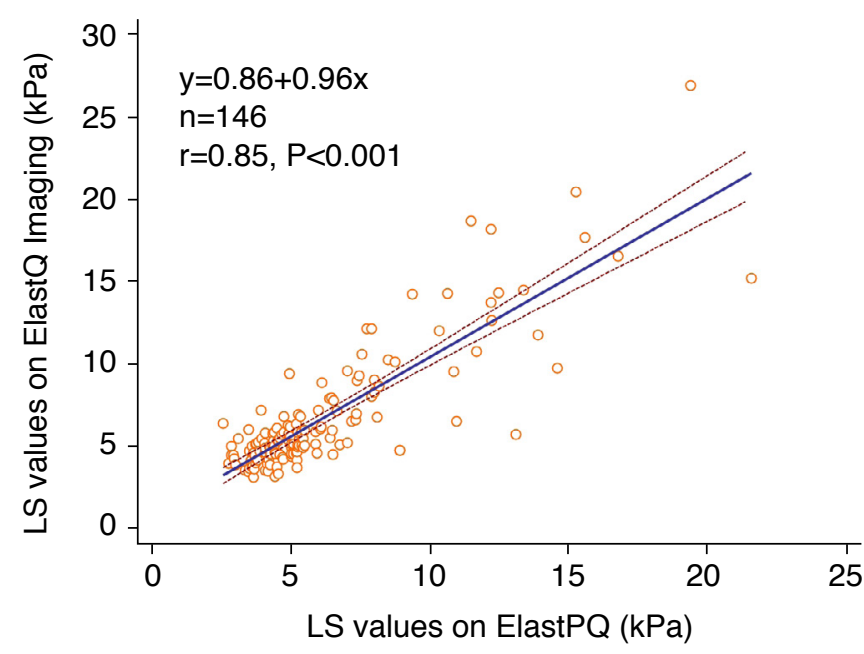

A

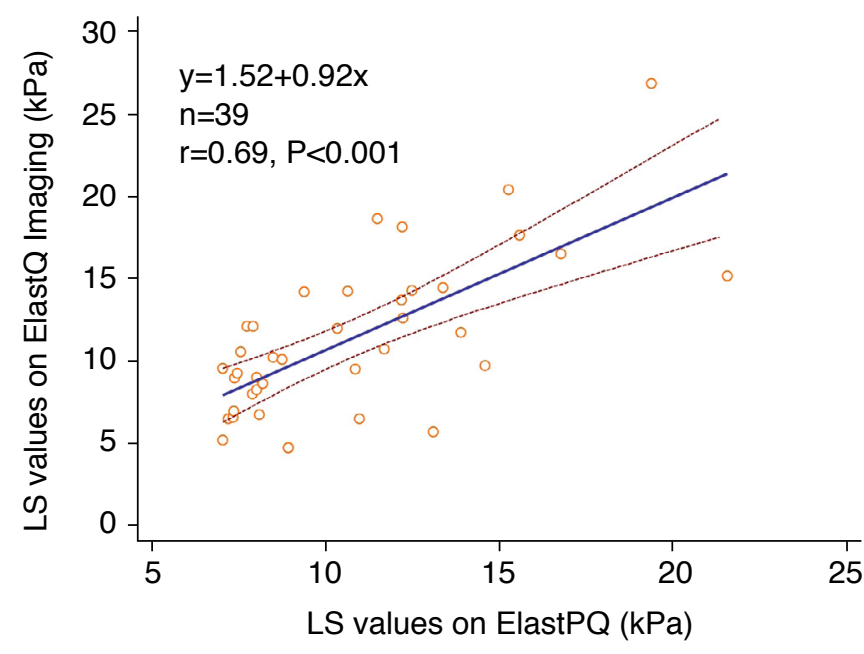

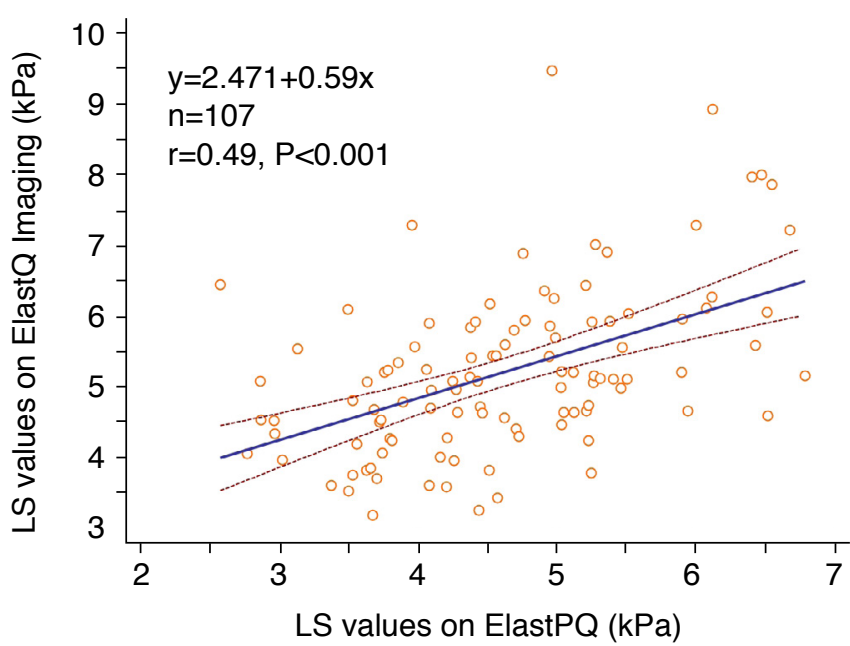

B

Fig. 4. Correlation of liver stiffness (LS) values between ElastPQ and ElastQ Imaging in the development group.

A-C. Scatter diagrams with lines show the linear regression between the $L S$ values obtained by ElastQ Imaging ( $y$-axis) and the $L S$ values obtained by ElastPQ ( $x$-axis) in the development group $(A, n=146)$, the subgroup without significant fibrosis $(B, n=107$, and the subgroup with significant fibrosis $(C, n=39)$. The solid line represents the regression line, and the dashed lines represent the $95 \%$ confidence intervals.

C 
techniques exhibited a strong positive correlation, and the linear regression equation for the $L S$ values obtained using ElastQ Imaging $(y)$ and that using ElastPQ $(x)$ was $y=0.85+0.96 x$. However, the estimated values in the validation study were not interchangeable with the real LS values of ElastQ Imaging because of the wide 95\% limits of agreement, particularly in the subgroup of patients with significant fibrosis.

In our study, no technical failure was observed for either SWE technique. Nevertheless, the LS measurements obtained using ElastPQ were less reliable than the measurements reported by previous studies $[26,38]$; however, this discrepancy may have been due to differences in the characteristics of the study populations (e.g., abdominal wall thickness) [39]. Importantly, the LS measurements obtained using ElastQ Imaging were more reliable than those obtained using ElastPQ. Furthermore, ElastQ Imaging showed a lower CV than that of ElastPQ, suggesting higher repeatability. The

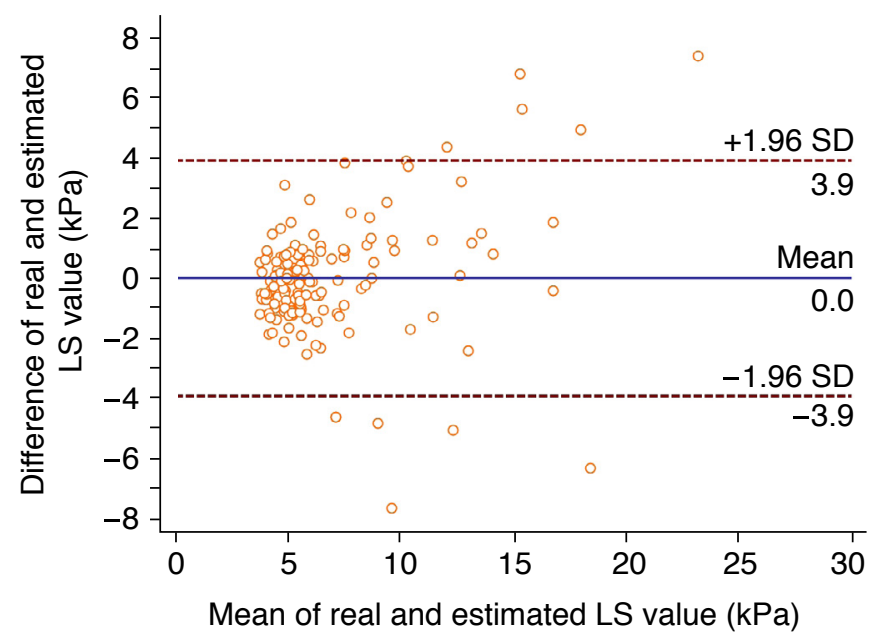

A

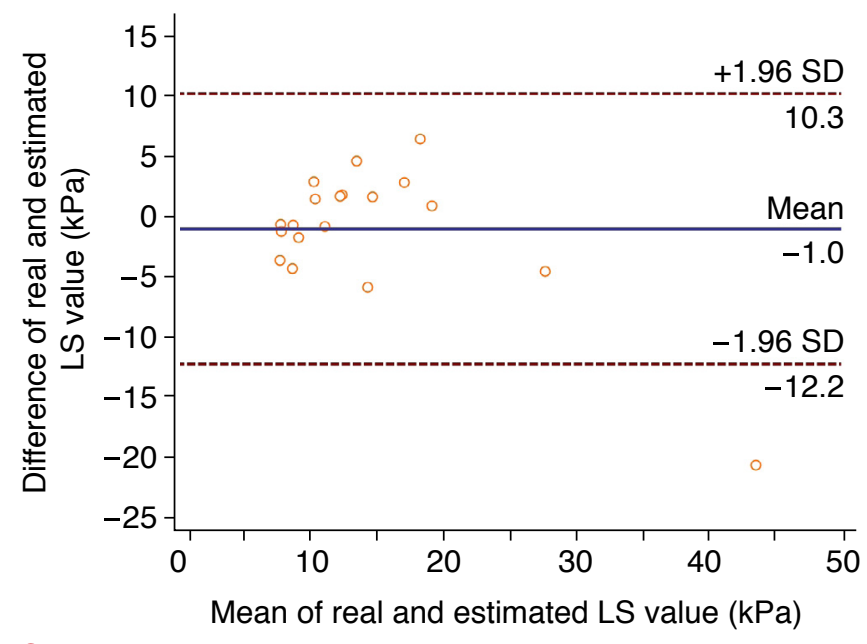

confidence map of ElastQ Imaging may have contributed to this higher repeatability. Although previous studies have used other maps (e.g., propagation maps) that serve a similar purpose and may improve reliability [31], the confidence map of ElastQ Imaging allows for the visualization of a color-coded value $(0 \%-100 \%)$ that indicates the confidence level based on shear wave propagation, while the elastographic map is displayed on the same screen. This allows operators to more easily determine the appropriate location of the ROls on the elastographic map.

Woo et al. [29] reported that the initially introduced 2D-SWE system, supersonic imaging (SSI), involved a longer measurement duration than did VTQ, the first developed PSWE technique. In contrast, our results demonstrated that the acquisition time of the latest 2D-SWE system, ElastQ Imaging, was significantly shorter than that of the PSWE technique, ElastPQ. The difference in acquisition times could be attributed to the higher B-mode frame

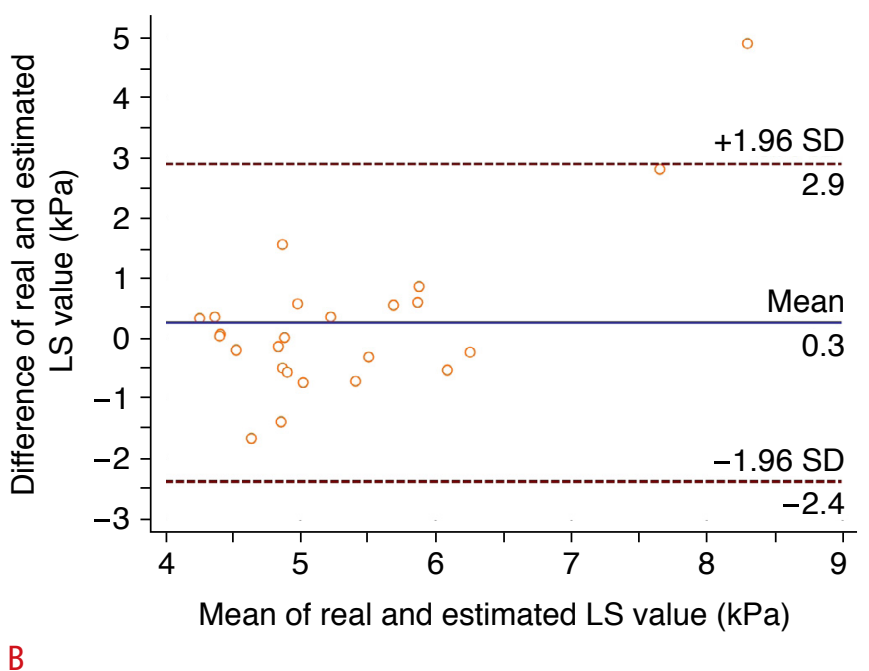

Fig. 5. Bland-Altman plots between the real and estimated liver stiffness (LS) values of ElastQ Imaging in the validation group. A-C. Differences ( $y$-axis) and mean values ( $x$-axis) between the real and estimated LS values of ElastQ Imaging were plotted. The 95\% limits of agreement in the validation group (A), subgroup without significant fibrosis (B), and subgroup with significant fibrosis (C) ranged from $-3.9 \mathrm{kPa}$ to $3.9 \mathrm{kPa}$ (mean, $0.0 \mathrm{kPa}$ ), from $-2.4 \mathrm{kPa}$ to $2.9 \mathrm{kPa}$ (mean, $0.3 \mathrm{kPa}$ ), and from $-2.2 \mathrm{kPa}$ to $10.3 \mathrm{kPa}$ (mean, $-1.0 \mathrm{kPa}$ ), respectively. The solid line indicates the mean difference. The top and bottom dashed lines correspond to the upper and lower margins of the $95 \%$ limits of agreement. SD, standard deviation. 
rate (approximately 20-30 frames per second) and multiple ROls in an elastographic box in ElastQ Imaging. Moreover, ElastQ Imaging provides the largest elastographic box among all 2D-SWE systems $[29,30]$, which may enable the reflection of a larger area of liver tissue and more robust fibrosis estimation. Additionally, multiple ROIs could be placed in the box, although studies have yet to determine the precise number of ROls that could be placed in the elastographic box.

Our results demonstrated that the LS values obtained using ElastQ Imaging were significantly higher than those obtained using ElastPQ, which is similar to the results of previous studies $[29,38]$. Sporea et al. [38] demonstrated that the mean LS values obtained using ElastPQ were significantly lower than those obtained using VTQ, even though both ElastPQ and VTQ are pSWE techniques. In a study conducted by Woo et al. [29], the LS values obtained using SSI were significantly higher than those obtained using VTQ. Similarly, in a phantom study that compared four different SWE techniques including TE, pSWE, and two types of 2D-SWE, the obtained LS values differed significantly among the techniques [39]. Therefore, distinct cutoff values for discriminating among the different stages of liver fibrosis should be presented for each SWE technique so that they can be used to detect and monitor the disease. However, the cutoff value for ElastQ Imaging for staging hepatic fibrosis using liver biopsy has not been established.

Our study had several limitations. First, this was a retrospective study, and patients with underlying liver disease of various etiologies were included. The causes of liver fibrosis and cirrhosis vary, and this variation may have affected $L S$ values. Second, the diagnostic performance of the two SWE techniques could not be evaluated and compared due to the lack of a reference standard (e.g., a liver biopsy). Further studies of patients with chronic liver disease of a single etiology who undergo liver biopsy as a reference standard are needed to determine the diagnostic performance of the two SWE techniques. Third, we included a large number of patients without chronic liver disease and a small number of patients with significant fibrosis or cirrhosis. Although this reflects actual clinical circumstances, it might have caused spectral bias. In addition, there was a noteworthy difference in the proportion of patients with significant fibrosis $(\geq \mathrm{F} 2)$ between the development group $(26.7 \%$ [39/146]) and the validation group (44.2\% [19/43]). Last, intraand inter-observer reproducibility was not evaluated, although repeatability was evaluated using $\mathrm{CV}$ s.

In conclusion, ElastQ Imaging may be a reliable and fast tool for the evaluation of liver fibrosis. ElastQ Imaging could be a viable alternative to liver biopsy in a clinical setting where rapid and accurate evaluation is required. However, further validation studies using liver biopsy samples as a reference standard are still needed.
ORCID: Sang Min Lee: https://orcid.org/0000-0001-7719-3849; Min-Jeong Kim: https://orcid.org/0000-0002-7484-5896; Jeong Hee Yoon: https://orcid.org/00000002-9925-9973; Wonju Hong: https://orcid.org/0000-0001-6891-5483; Hong II Ha: https://orcid.org/0000-0001-9050-7486; Kwanseop Lee: https://orcid.org/00000002-8951-4512; Ji-Young Choe: https://orcid.org/0000-0001-7967-8487; Jung Woo Lee: https://orcid.org/0000-0001-6942-9655; Sam-Youl Yoon: https://orcid.org/00000002-4624-1497; Junhee Han: https://orcid.org/0000-0001-5736-8752

\section{Author Contributions}

Conceptualization: Lee SM, Kim MJ. Data acquisition: Lee SM, Kim MJ, Hong W. Data analysis or interpretation: Lee SM, Kim MJ, Yoon JH, Choe JY, Han J. Drafting of the manuscript: Lee SM, Kim MJ, Yoon JH. Critical revision of the manuscript: Ha HI, Lee K, Lee JW, Yoon SY. Approval of the final version of the manuscript: all authors.

\section{Conflict of Interest}

No potential conflict of interest relevant to this article was reported.

\section{Acknowledgments}

This research was supported by the Hallym University Research Fund 2018 (HURF-2018-09).

\section{References}

1. Barr RG, Ferraioli G, Palmeri ML, Goodman ZD, Garcia-Tsao G, Rubin J, et al. Elastography assessment of liver fibrosis: Society of Radiologists in Ultrasound Consensus Conference Statement. Radiology 2015;276:845-861.

2. Lozano R, Naghavi M, Foreman K, Lim S, Shibuya K, Aboyans V, et al. Global and regional mortality from 235 causes of death for 20 age groups in 1990 and 2010: a systematic analysis for the Global Burden of Disease Study 2010. Lancet 2012;380:2095-2128.

3. Blachier M, Leleu H, Peck-Radosavljevic M, Valla DC, RoudotThoraval F. The burden of liver disease in Europe: a review of available epidemiological data. J Hepatol 2013;58:593-608.

4. Intraobserver and interobserver variations in liver biopsy interpretation in patients with chronic hepatitis C. The French METAVIR Cooperative Study Group. Hepatology 1994;20(1 Pt 1):15-20

5. Stotland BR, Lichtenstein GR. Liver biopsy complications and routine ultrasound. Am J Gastroenterol 1996;91:1295-1296.

6. Regev A, Berho M, Jeffers LJ, Milikowski C, Molina EG, Pyrsopoulos $N T$, et al. Sampling error and intraobserver variation in liver biopsy in patients with chronic HCV infection. Am J Gastroenterol 2002:97:2614-2618.

7. Jeong WK, Lim HK, Lee HK, Jo JM, Kim Y. Principles and clinical application of ultrasound elastography for diffuse liver disease. Ultrasonography 2014;33:149-160.

8. Castera L, Vergniol J, Foucher J, Le Bail B, Chanteloup E, Haaser M, 
et al. Prospective comparison of transient elastography, Fibrotest, APRI, and liver biopsy for the assessment of fibrosis in chronic hepatitis C. Gastroenterology 2005;128:343-350.

9. Tsochatzis EA, Gurusamy KS, Ntaoula S, Cholongitas E, Davidson BR, Burroughs AK. Elastography for the diagnosis of severity of fibrosis in chronic liver disease: a meta-analysis of diagnostic accuracy. J Hepatol 2011;54:650-659.

10. $\mathrm{Yu} \mathrm{JH}$, Lee $\mathrm{JI}$. Current role of transient elastography in the management of chronic hepatitis B patients. Ultrasonography 2017;36:86-94.

11. Sandrin L, Fourquet B, Hasquenoph JM, Yon S, Fournier C, Mal

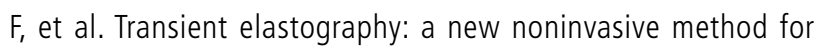
assessment of hepatic fibrosis. Ultrasound Med Biol 2003;29:17051713.

12. Castera L, Foucher J, Bernard PH, Carvalho F, Allaix D, Merrouche $W$, et al. Pitfalls of liver stiffness measurement: a 5-year prospective study of 13,369 examinations. Hepatology 2010;51:828-835.

13. Hong EK, Choi YH, Cheon JE, Kim WS, Kim IO, Kang SY. Accurate measurements of liver stiffness using shear wave elastography in children and young adults and the role of the stability index. Ultrasonography 2018;37:226-232.

14. Ryu H, Ahn SJ, Yoon JH, Lee JM. Reproducibility of liver stiffness measurements made with two different 2-dimensional shear wave elastography systems using the comb-push technique. Ultrasonography 2019;38:246-254.

15. Ryu H, Ahn SJ, Yoon JH, Lee JM. Inter-platform reproducibility of liver stiffness measured with two different point shear wave elastography techniques and 2-dimensional shear wave elastography using the comb-push technique. Ultrasonography 2019;38:345-354.

16. Yoo J, Lee JM, Joo I, Yoon JH. Assessment of liver fibrosis using 2-dimensional shear wave elastography: a prospective study of intra- and inter-observer repeatability and comparison with point shear wave elastography. Ultrasonography 2020;39:52-59.

17. Friedrich-Rust M, Poynard T, Castera L. Critical comparison of elastography methods to assess chronic liver disease. Nat Rev Gastroenterol Hepatol 2016;13:402-411.

18. Bota S, Herkner H, Sporea I, Salzl P, Sirli R, Neghina AM, et al. Meta-analysis: ARFI elastography versus transient elastography for the evaluation of liver fibrosis. Liver Int 2013;33:1138-1147.

19. Leung VY, Shen J, Wong VW, Abrigo J, Wong GL, Chim AM, et al. Quantitative elastography of liver fibrosis and spleen stiffness in chronic hepatitis B carriers: comparison of shear-wave elastography and transient elastography with liver biopsy correlation. Radiology 2013;269:910-918.

20. Cassinotto C, Lapuyade B, Mouries A, Hiriart JB, Vergniol J, Gaye $D$, et al. Non-invasive assessment of liver fibrosis with impulse elastography: comparison of spersonic shear imaging with ARFI and FibroScan ${ }^{\circledR}$. J Hepatol 2014;61:550-557.
21. Hu X, Qiu L, Liu D, Qian L. Acoustic radiation force impulse (ARFI) elastography for noninvasive evaluation of hepatic fibrosis in chronic hepatitis B and C patients: a systematic review and metaanalysis. Med Ultrason 2017;19:23-31.

22. Ahn SJ, Lee JM, Chang W, Lee SM, Kang HJ, Yang H, et al. Prospective validation of intra- and interobserver reproducibility of a new point shear wave elastographic technique for assessing liver stiffness in patients with chronic liver disease. Korean J Radiol 2017; 18:926-935.

23. Lee JE, Shin KS, Cho JS, You SK, Min JH, Kim KH, et al. Non-invasive assessment of liver fibrosis with ElastPQ: comparison with transient elastography and serologic fibrosis marker tests, and correlation with liver pathology results. Ultrasound Med Biol 2017;43:25152521.

24. Lu Q, Lu C, Li J, Ling W, Qi X, He D, et al. Stiffness value and serum biomarkers in liver fibrosis staging: study in large surgical specimens in patients with chronic hepatitis B. Radiology 2016;280:290-299.

25. Ma JJ, Ding H, Mao F, Sun HC, Xu C, Wang WP. Assessment of liver fibrosis with elastography point quantification technique in chronic hepatitis B virus patients: a comparison with liver pathological results. J Gastroenterol Hepatol 2014;29:814-819.

26. Yoo H, Lee JM, Yoon JH, Lee DH, Chang W, Han JK. Prospective comparison of liver stiffness measurements between two point shear wave elastography methods: virtual touch quantification and elastography point quantification. Korean J Radiol 2016;17:750757.

27. Park SH, Kim SY, Suh CH, Lee SS, Kim KW, Lee SJ, et al. What we need to know when performing and interpreting US elastography. Clin Mol Hepatol 2016;22:406-414.

28. Samir AE, Dhyani M, Vij A, Bhan AK, Halpern EF, Mendez-Navarro $J$, et al. Shear-wave elastography for the estimation of liver fibrosis in chronic liver disease: determining accuracy and ideal site for measurement. Radiology 2015;274:888-896.

29. Woo H, Lee JY, Yoon JH, Kim W, Cho B, Choi BI. Comparison of the reliability of acoustic radiation force impulse imaging and supersonic shear imaging in measurement of liver stiffness. Radiology 2015;277:881-886.

30. Lee SM, Lee JM, Kang HJ, Yang HK, Yoon JH, Chang W, et al. Liver fibrosis staging with a new 2D-shear wave elastography using comb-push technique: applicability, reproducibility, and diagnostic performance. PLoS One 2017;12:e0177264.

31. Lee ES, Lee JB, Park HR, Yoo J, Choi Jl, Lee HW, et al. Shear wave liver elastography with a propagation map: diagnostic performance and inter-observer correlation for hepatic fibrosis in chronic hepatitis. Ultrasound Med Biol 2017;43:1355-1363.

32. Poynard T, Munteanu M, Luckina E, Perazzo H, Ngo Y, Royer L, et al. Liver fibrosis evaluation using real-time shear wave elastography: applicability and diagnostic performance using methods without a 
gold standard. J Hepatol 2013;58:928-935.

33. Ferraioli G, Filice C, Castera L, Choi BI, Sporea I, Wilson SR, et al. WFUMB guidelines and recommendations for clinical use of ultrasound elastography: Part 3: liver. Ultrasound Med Biol 2015;41:1161-1179.

34. Yoon JH, Lee JM, Woo HS, Yu MH, Joo I, Lee ES, et al. Staging of hepatic fibrosis: comparison of magnetic resonance elastography and shear wave elastography in the same individuals. Korean J Radiol 2013;14:202-212.

35. Yamanaka N, Kaminuma C, Taketomi-Takahashi A, Tsushima $Y$. Reliable measurement by virtual touch tissue quantification with acoustic radiation force impulse imaging: phantom study. J Ultrasound Med 2012;31:1239-1244.
36. Bland JM, Altman DG. Statistical methods for assessing agreement between two methods of clinical measurement. Lancet 1986;1:307310.

37. Musana KA, Yale SH, Abdulkarim AS. Tests of liver injury. Clin Med Res 2004;2:129-131.

38. Sporea I, Bota S, Gradinaru-Tascau O, Sirli R, Popescu A. Comparative study between two point shear wave elastographic techniques: acoustic radiation force impulse (ARFI) elastography and ElastPQ. Med Ultrason 2014;16:309-314.

39. Lee SM, Chang W, Kang HJ, Ahn SJ, Lee JH, Lee JM. Comparison of four different shear wave elastography platforms according to abdominal wall thickness in liver fibrosis evaluation: a phantom study. Med Ultrason 2019;21:22-29. 